\title{
Identity Changes of the Mentawai Tribe in the Novel Burung Kayu by Niduparas Erlang
}

\author{
Dian Susilastri ${ }^{1}$, Budi Agung Sudarmanto ${ }^{2}$ \\ \{dian.susilastri@kemdikbud.go.id ${ }^{1}$, budi.agung@kemdikbud.go.id ${ }^{2}$ \} \\ Balai Bahasa Sumatera Selatan, Indonesia ${ }^{12}$
}

\begin{abstract}
The novel Burung Kayu (Wooden Bird) by Niduparas Erlang (2020) presented the problem of identity changes of a Mentawai tribal child named Legeumanai, from primitive to modern life, then back to jungle life. The changes in identity were analyzed by Hall's cultural identity theory, in which cultural identity was seen as always in process and non-essentialist in nature. The purpose of this research was to describe the representation of identity changes of the Legeumanai character in the novel. Data obtained from the facts of the story in the novel. The data analysis was carried out by using the descriptive analysis method. The results of the analysis showed that the changes experienced by Legeumanai from childhood to adulthood symbolize changes in the Mentawai ethnicity.
\end{abstract}

Keywords: identity, identity changes, Mentawai tribe.

\section{Perubahan Identitas Masyarakat Mentawai dalam Novel Burung Kayu Karya Niduparas Erlang}

\begin{abstract}
Abstrak. Novel Burung Kayu karya Niduparas Erlang (2020) menyuguhkan persoalan perubahan identitas seorang anak suku Mentawai bernama Legeumanai, dari kehidupan primitif ke modern, kemudian kembali lagi ke kehidupan rimba. Perubahan identitas tersebut dianalisis dengan teori identitas budaya Hall, di mana identitas budaya dipandang selalu berproses dan bersifat non-esensialis. Tujuan penelitian ini adalah menggambarkan representasi perubahan identitas tokoh Legeumanai dalam novel tersebut. Data diperoleh dari fakta-fakta cerita yang ada dalam novel. Analisis data dilakukan dengan metode deskriptif analisis. Hasil yang analisis menunjukkan bahwa perubahan yang dialami tokoh Legeumanai sejak dari kecil hingga dewasa menyimbolkan perubahan budaya etnis Mentawai.
\end{abstract}

Kata kunci: identitas, perubahan identitas, suku Mentawai .

\section{Pendahuluan}

Suku Mentawai merupakan salah satu suku yang dalam pandangan orang Barat disebut sebagai suku 'primitif' Melayu Indonesia yang merupakan campuran ras Melayu dan Veddoid [1]. Mereka mendiami Pulau Siberut dan pulau kecil lain, di Kepulauan Mentawai. Wilayah itu merupakan daerah kepulauan terluar Indonesia di barat Pulau Sumatra, tepatnya di Provinsi Sumatra Barat yang 
dikelilingi oleh Samudera Hindia Belanda. Pada masa lalu, diperkirakan kepulauan tersebut--yang disebut Mantawei (dan pulau-pulau lain di luar Pulau Sumatra)--merupakan ujung daratan Pulau Sumatra yang yang terseret ke tengah lautan. Bagian puncaknya terus ditumbuhi pohon dan semaksemak yang diperkirakan sebagai tempat yang terisolasi [2]. Kini, pulau kecil dengan penduduk sekitar 92.021 jiwa pada tahun 2020 tersebut menyimpan banyak keunikan dan misteri sebuah etnis di alam yang eksotis. Meskipun kini Mentawai dianggap sebagai aset pariwisata budaya [3], 'keprimitifan' Mentawai masih terjaga.

Suku ini dikenal dengan tradisi meramu dedaunan, beternak, berladang, dan berburu dengan mengandalkan kehidupannya dari ketersediaan alam dan lingkungan. Mereka pandai menjaga keseimbangan ekosistem fauna dengan melakukan perburuan hewan, tetapi melakukan upacara sabulungan untuk menjaga/mengontrol agar fauna dan flora tetap berkembang dengan baik [4]. Mereka cenderung tidak mengenal hidup bercocok tanam. Makanan pokok mereka adalah sagu dan umbi. Hidup mereka berkelompok dan dalam lingkungan uma, meskipun masih menjalani hidup dengan pola nomaden. Uma adalah arsitektur tradisional Mentawai sebagai tempat tinggal berdasarkan garis patrilineal [5]. Hal tersebut sesuai dengan kata Mentawai yang berasal dari kata $s i$ manteu atau laki-laki [1] yang dapat dikatakan mencerminkan garis keturunan ayah.

Orang Mentawai hidup dengan menyeimbangkan kehidupan makrokosmos dan mikrokosmos. Mereka yang masih hidup di uma-uma di rimba pedalaman, masih memercayai kehidupan dinamisme dan animisme dalam bentuk kepercayaan yang disebut Arat Sabulungan [5]. Arwah para leluhur (baik manusia, tumbuhan, maupun hewan), memiliki peran yang penting dalam dunia religius suku Mentawai. Di dalam acara ritual suku Mentawai, ada sikerei, yaitu pemimpin upacara adat sekaligus dukun yang dianggap sakti, mampu meramu obat, dan menyembuhkan orang sakit, serta pandai mengenali alam gaib. Jabatan sikerei bukan keturunan dan tidak bisa dipelajari, tetapi mendapat panggilan jiwa dan dianggap telah dipilih oleh leluhur. Untuk ditasbihkan menjadi sikerei, orang harus melalui sebuah prosesi menari di atas bara api hingga semalam suntuk sambil merapal mantra-mantra yang disebut muturuk. Muturuk merupakan bentuk simbolisasi kehidupan masyarakat suku Mentawai [3].

Muturuk di dalam novel Burung Kayu dibagi dalam empat episode. Tiga episode awal menampilkan muturuk dengan berfokus pada calon sikerei muda bernama Legeumanai yang bermetamorfose dari pemuda modern menjadi sikerei yang pakaiannya kabit dari kulit pohon dan berhias dedaunan dan tato-tato. Muturuk keempat adalah festival budaya yang diselenggarakan oleh pemerintah daerah. Mentawai dalam bingkai fakta sosial memang telah berubah menjadi komoditas pariwisata, termasuk uma yang telah pula menjadi modern dan komersial [6]. Sekilas gambaran kehidupan suku Mentawai tadi dituangkan dengan baik dalam novel Burung Кayu oleh Niduparas Erlang (Juli, 2020) [7].

Novel yang masih relatif baru tersebut menarik karena gaya penceritaan dan peristiwa-peristiwa yang terjadi mampu membawa pembaca larut dalam "keprimitifan" suasana yang didukung perilaku tokoh-tokoh yang dengan tradisi adat suku Mentawai pada masanya. Lompatan perubahan budaya tersebut memberi pengalaman tersendiri bagi pembaca, termasuk bagi Sikerei Muda bernama Legeumanai yang mengalami perubahan identitas akibat budaya lingkungan yang berubah-ubah. Asumsi dasar paradigma evolusionisme adalah setiap masyarakat budaya akan mengalami perubahan, dari tingkat yang sederhana ke tingkat lebih kompleks [8].

Identitas budaya dapat dilihat dari dua sudut pandang, yaitu identitas budaya sebagai wujud (identity as being) dan identitas budaya sebagai proses menjadi (identity as becoming) [9]. Dalam pengertian pertama, identitas budaya dilihat sebagai satu bentuk dasar seseorang yang berada dalam diri banyak orang, dalam arti memiliki kesamaan sejarah dan leluhur/akar budaya. Identitas ini bersifat esensialis. Cara pandang esensialis ini mengidentifikasi ciri fisik atau lahiriah sebagai suatu kelompok. Pengertian kedua, menekankan bahwa identitas itu 
selalu berproses, berubah-ubah karena perubahan sejarah, kebudayaan, dan kekuasaan. Indentitas ini bersifat non-esensialis. Stuart Hall menolak definisi identitas budaya esensialis, alasannya seperti halnya segala sesuatu yang bersifat historis, identitas budaya mengalami transformasi yang terus-menerus, dan larut dalam perubahan kekuasaan, kebudayaan, dan sejarah [10]. Pada dasarnya, identitas budaya nyaris selalu bersifat non-esensialis, sejalan dengan paradigma evolusionisme. Identitas akan terlihat dalam bentuk representasi, yaitu suatu proses untuk memproduksi makna dari konsep yang ada di pikiran (mental representation) melalui bahasa (language/sign) [11].

Identitas adalah masalah memandang dan dipandang oleh orang lain yang mengonstruksinya. Dengan demikian, sesuatu yang dibahasakan atau diwacanakan oleh tokoh-tokoh di sekelilingnya mengenai Legeumanai, menjadi pembangun identitasnya. Tentu saja yang disajikan dalam artikel ini adalah deskripsi sikap dan pandangan tokoh lain yang berkaitan dengan identitas Legeumanai. Substansi yang berkaitan dengan konstruksi identitas Legeumanai disajikan dari beberapa sudut pandang aspek perilaku suku Mentawai dalam fakta cerita, yaitu ideologi, struktur sosial, teknoekonomi, dan kepribadian dalam ranah sosial maupun psikobiologisnya [12]. Dari deskripsi tersebut akan terlihat untaian perubahan identitas Legeumanai.

Studi yang membahas tentang budaya Mentawai telah banyak dilakukan. Beberapa di antaranya, yaitu dilakukan oleh Munaf dkk. (2001) yang membahas tentang tato yang menjadi ciri khas masyarakat tradisional Mentawai dalam kajian semiotik dan mitologis [5]. Dalam penelitian tersebut, pemahaman terhadap tato tradisional Mentawai dilakukan secara interdisipliner, yaitu tato sebagai karya seni rupa dan dari aspek sosial budaya, yaitu dari segi mitos dan nilai sastra lisan yang melatarbelakangi pemakaian motif tato.

Penelitian lain tentang Mentawai oleh Rosyani (2013), yaitu penelusuran penghapusan kepercayaan masyarakat Mentawai atau Arat Sabulungan oleh pemerintah Indonesia tahun 1954 [13]. Arat Sabulungan dilarang hidup di masyarakat, menyusul kebijakan pemerintah yang menghapuskan segala bentuk aliran kepercayaan di Indonesia karena dianggap bertentangan dengan agama-agama wahyu. Masyarakat Mentawai dipaksa untuk memilih agama Islam atau Kristen Protestan dan tidak boleh menjalankan ritual Arat Sabulungan lagi. Hasil penelitian lain tentang Mentawai, yaitu tentang tradisi pembuatan kabit atau cawat dari kulit kayu yang diteliti oleh Handini (2007). Kabit merepresentasikan aktivitas pembuatan pakaian pada zaman neolitik karena dianalogikan dengan temuan pemukul kayu di Sulawesi berupa alat untuk memipihkan kulit bayu sebagai bahan dasar kabit [14]. Ulita (2017) menelisik tentang warna-warna khas yang dipakai masyarakat Mentawai khususnya pada upacara adat Muturuk. Bagi etnis Mentawai warna merupakan salah satu unsur visual atau rupa yang dipercaya memiliki kekuatan dapat memengaruhi seseorang atau sesuatu [3]. Identitas Mentawai dalam penelitian Ulita ini direpresentasikan melalui warna-warna pada pakaian dan aksesoris yang dipakainya.

Identitas Mentawai dari beberapa penelitian di atas terepresentasi lewat beberapa media, yaitu tato di badan, kepercayaan arat sabulungan, pakaian tradisional kabit, dan warna-warna khas Mentawai dalam adat kesenian muturuk. Hasil penelitian tersebut merupakan fakta sosial. Melalui novel Burung Kayu karya Niduparas Erlang, Mentawai kembali dihadirkan, tetapi dalam bingkai fakta cerita sebuah fiksi. Urgensi penelitian ini, yaitu menyuguhkan sebuah pola perubahan identitas budaya seseorang, yang nyaris selalu berubahubah seiring dengan perubahan kekuasaan, kebudayaan, sejarah, atau alam. 


\section{Metode}

Penelitian ini merupakan penelitian dengan pendekatan kualitatif dan analisis teks sebagai metodenya [15]. Data sebagai objek materi secara keseluruhan berasal/bersumber dari buku novel Burung Kayu karya Niduparas Erlang (2020). Data yang dibutuhkan adalah data yang berkaitan dengan pengonstruksi identitas tokoh yang menjadi fokus utama, yaitu Legeumanai. Teknik pengumpulan data dilakukan dengan mengklasifikasi kata, klausa, kalimat, paragraf, dan wacana yang mendukung fakta cerita (tokoh, alur, dan latar) dan sesuai dengan tujuan penelitian. Kemudian, data yang sudah diklasifikasi dianalisis dengan teknik deskriptif analitik [15]. Dalam penelitian sebuah karya sastra, temuan-temuan bersumber dari teks novel itu sendiri. Fokus pengamatan, yakni pada perjalanan hidup tokoh Legeumanai, sejak kecil hingga menjadi dewasa dan mengalami berbagai perubahan kehidupan. Fakta-fakta cerita yang membangun jalannya cerita merangkai sebuah perubahan identitas anak suku Mentawai yang juga bermakna sebagai perubahan identitas etnis Mentawai.

\section{Hasil dan Pembahasan}

Kehadiran Legeumanai dalam cerita tidak seintensif ayah sambungnya, yaitu Saengrekerei yang dominan. Namun, Legeumanai mengalami perubahan hidup yang drastis. Berawal sebagai anak rimba yang sederhana, Legeumanai lalu mengikuti orang tuanya hidup di barasi, merantau di kota untuk menuntut ilmu, bekerja di kota, tetapi tiba-tiba dalam suatu peristiwa yang tidak biasa, ia terpanggil menjadi sikerei, kembali ke pedalaman, dan karena campur tangan pemerintah, Legeumanai harus mengomunikasikan antara pengobatan tradisionalnya sebagai sikerei dengan ilmu pengobatan medis sebagai sesuatu yang berimbang. Pada ujung cerita, budaya etnis Mentawai benarbenar larut dalam kekuasaan pemerintah yang harus mengikuti alur pembangunan pemerintah. Budaya Mentawai dijadikan sebagai sebuah atraksi dalam pertunjukan di sebuah panggung festival.

\subsection{Pandangan tokoh lain terhadap Legeumanai}

Tokoh yang memiliki relasi intensif dengan Legeumanai adalah Saengrekerei, Taksilitoni, para sikerei tua, Bagaiogok, dan Maria Saroro. Masing-masing mereka memiliki peran dalam membentuk identitas Legeumanai berdasarkan perilaku/sikap mereka.

\section{A. Saengrekerei}

Hubungan Saengrekerei dengan Legeumanai sesungguhnya adalah paman dan keponakan. Saengrekerei menikahi istri mendiang ayahnya (Bagaiogok). Perhatian dan tanggung jawab Saengrekerei terhadap Legeumanai sangat besar selayaknya anak kandung. Ia memiliki harapan besar terhadap kesuksesan Legeumanai terutama dalam hal pendidikan dan masa depan. Baginya, kekalahan uma-nya dari uma tetangga ketika masih tinggal di rimba pedalaman (Legeumanai masih kecil), terus menjadi obsesinya hingga Legeumanai dewasa. Baginya, meskipun burung kayu enggang hitam telah ditenggerkan di puncak pohon katuka, tetapi kematian kakaknya ketika menenggerkan burung kayu membuat ia merasa belum mencapai kemenangan dalam adu pako dengan uma tetangga. Obsesinya baru terpenuhi ketika ia berhasil mendidik Legeumanai hingga ia lulus kuliah dan bekerja dalam bidang teknologi di kota. Bagi Saengrekerei keberhasilan Legeumanai itulah kemenangan pako yang sesungguhnya. Saengrekerei dalam hal ini secara tidak langsung 
menjadikan Legeumanai sebagai sarana untuk mencapai obsesi, meskipun ia tulus dalam membesarkan Legeumanai. Segala pengetahuan tentang leluhur mereka yang gagah berani serta tanah kekuasaan mereka telah jauh hari diberitahukan oleh Saengrekerei kepada Legeumanai agar tidak terlupa.

Ketika Legeumanai harus pulang ke barasi karena ibunya (Taksilitoni) sakit, dan Legeumanai pun menderita demam tinggi, Saengrekerei terpaksa membawa mereka berdua kembali ke uma di hutan pedalaman untuk mencari penyembuhan karena dokter tidak sanggup mengobatinya. Ia berharap sikerei di rimba mampu menyembuhkan mereka berdua. Dalam kondisi itu, Legeumanai dianggap mendapat panggilan leluhur untuk menjadi sikerei. Saengrekerei menyetujui dan menjadikan Legeumanai sebagai sikerei muda, suatu peradaban yang sangat berbeda dengan kehidupan yang ia jalani selama ini. Legeumanai telah mencapai kehidupan yang baik dan modern di kota dan tidak mengenal uma dan bahasa serta peradabannya, tiba-tiba berubah menjadi pemuka suku dengan peradaban primitif.

Saengrekerei adalah pejabat di barasi yang harus dapat mengkomunikasikan pesan pemerintah pada masyarakat Mentawai terutama yang tinggal di barasi, termasuk sistem pengobatan. Legeumanai yang telah menjadi sikerei dan hidup di barasi bersama Saengrekerei pun dapat menegosiasikan antara pengobatan dengan cara meramu dan bantuan leluhur versi sikerei dengan pengobatan medis yang modern.

\section{B. Taksilitoni}

Ibu atau baboi Legeumanai bernama Taksilitoni. Tidak berbeda jauh dengan sikap Saengrekerei, ia pun memiliki obsesi terhadap Legeumanai agar menjadi orang yang pandai dan sukses, jadi harus bersekolah dan belajar walaupun di tempat jauh dari keluarga. Meskipun, pada awalnya, kematian Bagaiogok telah menumbuhkan benih balas dendam dalam diri Taksilitoni. Ia bersedia ikut Saengrekerei merantau ke barasi karena berharap kelak Legeumanai dewasa dapat membalas dendam kematian ayahnya. Namun, justru sakitnya Taksilitoni yang menjadikan Legeumanai kembali ke pangkuan uma di rimba pedalaman sebagai sikerei. Demikianlah jalan Taksilitoni membentuk identitas Legeumanai yang secara tidak langsung mengubah jalan hidup Legeumanai.

\section{Para Sikerei Tua}

Ketika Taksilitoni sakit keras berhari-hari dan Legeumanai mengalami demam tinggi, tidak ada pilihan lain bagi Saengrekerei untuk mengajak pulang ke uma di haribaan Sabulungan. Bersama Saengrekerei, para sikerei tua mendorong Legeumanai agar menjadi sikerei agar ibunya dan dirinya sendiri dapat sembuh. Para sikerei itu menganggap baha leluhur telah memilih Legeumanai menjadi sikerei. Lalu terjadilah tiga episode muturuk yang digambarkan dalam novel Burung Kayu. Para sikerei tua menganggap bahwa roh-roh sikerei dari berbagai uma berbagai masa tengah memberkati Legeumanai yang melompat-lompat ke dalam api dengan kaki yang tidak melepuh dan terus saja menari sambil merapalkan mantra-mantra magis yang tidak pernah dipelajari. Para sikerei tua sangat bangga pada Legeumanai yang berbakat menjadi sikerei muda.

Dari sikap tokoh lain tentang Legeumanai dapat dikatakan bahwa Legeumanai adalah tokoh yang memiliki perubahan identitas bukan oleh kehendaknya, tetapi kehendak atau kuasa di luar dirinya. Semua membawanya kepada kehidupan yang berubah secara drastis. Satu-satunya kehendak Legeumanai sendiri (yang terungkap dalam hati) berupa perasaan suka pada Maria Saroro tetapi bertepuk sebelah tangan. 


\subsection{Aspek perilaku etnis Mentawai sebagai fakta cerita}

Ada empat aspek perilaku etnis yang ditunjukkan dalam fakta cerita yang akan disampaikan dalam makalah ini. Itu pun yang memiliki relasi dengan perubahan identitas Legeumanai saja, yaitu ideologi, struktur sosial, teknoekonomi, dan kepribadian ranah sosial dan psikobiologis pada latar Mentawai yang digambarkan dalam novel. Ideologi suatu masyarakat mencakup semua kepercayaan, falsafah, nilai dan pengetahuan ilmiahnya. Struktur sosial berupa konfigurasi kelompok-kelompok yang mantap dan seperangkat norma dan aturan ideal. Teknoekonomi berupa cara benda-benda itu diorganisasikan dalam penggunaannya. Kepribadian setiap masyarakat memiliki suatu kode kognitif atau seperangkat kode/kaidah kognitif yang meliputi semua ranah/domain budaya yang menandai masyarakat itu.

\section{A. Ideologi}

Legeumanai kecil berada di habitus Mentawai yang memiliki ideologi berupa kepercayaan Arat Sabulungan yang memercayai roh-roh leluhur (manusia, hewan, dan tumbuhan) yang memiliki peran dalam kehidupan mereka. Mereka bisa dihadirkan bila memang diundang dalam sebuah ritual, baik adat pentasbihan maupun ritual penyembuhan. Sikerei memiliki peran penting dalam kehidupan religius etnis Mentawai. Pada saat Legeumanai sudah pindah di barasi, mereka harus memiliki agama yang diperbolehkan pemerintah. Saengrekerei mengajarkan sebuah prinsip yang sekuler demi kedamaian tentang hidup beragama kepada Legeumanai. Semua agama atau arat dianggap baik dan jangan dipertentangkan. Seiring perkembangan cara berpikir orang Mentawai yang mulai terbuka dan bebas memilih, perubahan nama pun menunjukkan identitas yang berubah-ubah. Legeumanai memiliki nama sesuai dengan lingkungan dan religinya, yaitu Legeumanai Sura'-Sabbeu, Agustinus Legeumanai Sura'-Sabbeu, atau Ahmad Legeumanai.

\section{B. Struktur Sosial}

Empat episode muturuk dalam novel merupakan salah satu ritual yang merepresentasikan suatu proses pembentukan struktur sosial Mentawai dalam novel. Dalam episode Muturuk 1, Muturuk 2, dan Muturuk 3 ditunjukkan adanya strata sosial dalam adat Mentawai. Hanya sikerei tua dan calon sikerei yang boleh masuk dalam lingkaran ritual tersebut. Itu pun mereka harus menggunakan atribut pakaian kabit dan tanda-tanda tato tertentu karena tato menunjukkan kewibawaan dan tingkat kepiawaian seseorang. Meskipun masih muda, Legeumanai masuk dalam lingkungan sikerei karena dianggap memiliki bakat dan panggilan leluhur sehingga pantas dijadikan sikerei dalam lingkungan tetua-tetua adat. Lingkungan struktur sosial telah membentuk identitas Legeumanai. Episode Muturuk 4 merupakan sebuah ironi upacara muturuk yang sakral menjadi sebuah ajang pertunjukan anak-anak.

\section{Teknoekonomi}

Ada satu media yang dianggap sebagai sebuah simbol keunggulan, yaitu patung burung enggang yang dipahat dengan pisau tajam terbuat dari kayu yang dicat berwarna hitam dan kuning. Dalam sebuah pako atau adu kemenangan, setiap kelompok uma yang berhasil menenggerkan burung kayu di puncak batang katuka yang menjulang tinggi, dianggap memenangkan pako. Menenggerkan burung kayu tidak bisa sembarangan karena ancaman selalu menghadang dari kelompok uma tetangga yang menjadi lawan. Mereka akan siap melempar tombak dan panah beracun ke tubuh pemasang burung kayu yang meliuk-liuk ditiup angin.

\section{Kepribadian ranah sosial dan psikobiologis}

Suku Mentawai memiliki masyarakat yang cenderung menjaga kehormatan diri sendiri maupun keluarga se-uma. Mereka rela mati demi harga diri dan kemenangan. Legeumanai sejak kecil sudah dibawa oleh Saengrekerei jauh ke barasi bahkan bersekolah di kota. Legeumanai tidak lagi mengenal 
kabit yang dipakai orang-orang Mentawai pedalaman. Bahkan, bahasa Mentawai pun ia secara sadar telah lupa. Legeumanai dewasa memang sudah tercerabut dari akar. Namun, ia yang secara supranatural dianggap mengalami suatu perubahan dalam dirinya, tiba-tiba harus menjadi tokoh religius di dunia yang telah lama ditinggalkannya.

\section{Simpulan}

Tokoh Legeumanai dalam novel Burung Kayu karya Niduparas Erlang mengalami evolusi identitas atau perubahan yang signifikan dalam kehidupannya. Mulai dari masa kanakkanak yang menjadi anak rimba, dewasa sebagai pemuda yang berpendidikan dan hidup modern di kota, kemudian harus kembali hidup di hutan Mentawai sebagai sikerei muda yang berada dalam dunia 'primitif'. Meskipun sebagai sikerei, Legeumanai dapat menyeimbangkan dan berkompromi antara pola hidup animisme-dinamisme di hutan dan tata cara hidup modern yang berasal dari pemerintah.

Legeumanai dianggap sebagai sebuah simbol perubahan identitas etnis Mentawai. Melalui perilaku yang ditunjukkan oleh orang-orang di sekitarnya serta aspek-aspek perilaku etnis Mentawai dalam fakta cerita yang ditunjukkan dalam novel, identitas Legeumanai dapat diketahui perubahannya. Aspek-aspek perilaku suku Mentawai tersebut, yaitu secara ideologi masih menganut kepercayaan Arat Sabulungan meskipun ketika berbaur dengan masyarakat beragama ia larut bersama mereka; struktur sosial yang direpresentasikan dalam upacara muturuk (1-3); unsur teknoekonomi dengan perwujudan menenggerkan burung kayu di puncak pohon katuka sebagai simbol kemenangan; dan bentuk kepribadian dalam ranah sosial maupun psikobiologis disimbolkan dalam diri Legeumanai yang sudah tercerabut dari akar tetapi kembali 'pulang' ke rimba asalnya.

Episode Muturuk 4 merupakan sebuah puncak penanda dari perubahan era primitif ke dunia modern. Bila Legeumanai dimetaforakan sebagai etnis Mentawai, ia kini mengalami perubahan identitas. Legeumanai harus menerima perubahan identitas dari leluhur yang menguasasinya, Mentawai pun harus menerima perubahan identitas bahwa dirinya merupakan aset wisata bagi negara penguasanya.

\section{Referensi}

[1] Loeb EM. Sumatra: Sejarah dan Masyarakatnya. Yogyakarta: Penerbit Ombak, 2013

[2] Marsden W. Sejarah Sumatra. Depok: Komunitas Bambu, 2013.

[3] Ulita N. Kajian Visual Warna Pada Kesenian Muturuk Mentawai. Narada J. Desain dan Seni. 2017; 4(3): 259-273.

[4] Tresno. 'Ute' Simagere (Tengkorak Bagi Roh): Hubungan Masyarakat dengan Primata Endemik di Mentawai. J. Antropol. Isu-isu Sos. Budaya. 2017; 19(1): 67-87.

[5] Munaf Y, et.all, Kajian Semiotik dan Mitologis terhadap Tato Masyarakat Tradisional Kepulauan Mentawai. Jakarta: Pusat Bahasa, Departemen Pendidikan Nasional, 2001.

[6] Kusbiantoro K, Anthonius R, Santosa I. Modernisasi dan Komersialisasi Uma Masyarakat Mentawai Sebuah Deskripsi Fenomenologis. J. Sosioteknologi, 2016; 15(2): 187-199.

[7] Erlang N. Burung Kayu. Padang-Jakarta: CV Teroka Gaya Baru, 2020.

[8] H. S. Ahimsa-Putra, Strukturalisme Levi-Strauss: Mitos dan Karya Sastra. Yogyakarta: Galang Press, 2009. 
[9] Hall S.. Cultural Identity and Diaspora, in Diaspora and Visual Culture: Representing Africans and Jews, 2014

[10] Sabbah S, Ayuningtyas P. Pemahaman Identitas dan Toleransi Keberagaman Budaya Mahasiswa Sastra Inggris UAI Melalui Puisi Multikultural Kesusasteraan Inggris: Sebuah Kajian Multikulturalisme. J. Al-AZHAR Indones. SERI Hum., 2018.

[11] Hall S. Representation: Cultural Representations and Signifying Practices. London: Sage Publications, 1997.

[12] Kaplan D, Manners RA. Teori Budaya. Yogyakarta: Pustaka Pelajar, 2012.

[13] Rosyani I. Kehidupan Arat Sabulungan dalam Masyarakat Tradisional Mentawai. Universitas Pendidikan Indonesia, 2013.

[14] Handini R. Tradisi Pembuatan Kabit dari Kulit Kayu Pada Suku Mentawai, Sumatera Barat. Amerta, 2007; 25(1): 39-47.

[15] Ratna NK. Teori, Metode, dan Teknik Penelitian Sastra. Yogyakarta: Pustaka Pelajar, 2013. 